\title{
Keeping the tires warm
}

\section{Research is a necessity for the Middle Eastern countries currently growing their knowledge economies, and it is the key to their achieving autonomous control of their people's healthcare. To sustain knowledge growth, policymakers need to learn to trust researchers while also insisting upon evidence for the advice they get from them.}

$I^{\mathrm{m}}$ magine the Grand Prix, engines racing on the grid, pit teams poised, and the spectators' applause gradually thinning as their impatience grows. Someone, somewhere has forgotten to bring the starting flag. This odd mood prevailed among the geneticists from 36 nations represented at the $3^{\text {rd }}$ Pan-Arab Human Genetics Conference organized in Dubai in the United Arab Emirates (http://www.cags.org.ae/3rdpahgc. html). Much of the discussion centered around presentations on science policy in the lectures, and it continued well into the subsequent evening's dhow excursion through the city. "Researchers must involve policymakers from the beginning, or the research will get shelved," we were told. "In return, policymakers must involve researchers." So far so good, but what happens if decision makers receive poor advice and fail to trust the scientists and physicians?

It's not just the recession that is causing these holdups. Many policymakers in the region have wisely heeded the calls for an enduring commitment of a substantial proportion of GNP for research (Nature 444, 33-34, 2006, and Nature 444, 35-36, 2006). Yet despite significant levels of new biomedical spending, researchers and physicians are still finding it hard to find funding for the human genetics most relevant to reducing mortality and economic, social and personal costs in the region. And this is a region in which the stars are particularly bright. Dozens of recent articles in this journal attest to regional clinical geneticists' superb ability to come up with the 'corner pieces' of the world jigsaw puzzle of the human genome by making use of their knowledge of the region's distinctive populations, large families and high consanguinity.

It is hard not to be astonished by the visionary institutions endowed in Saudi Arabia by King Abdullah-his eponymous University of Science and Technology and International Medical Research Center (KAUST and KAIMRC, respectively). Also impressive is the solid chunk of the nation's GNP pledged to research by the Qatar Foundation and its National Research Fund. Still, we recognize that there is no certain relationship of input quantity to output quality. From the point of view of this journal, which looks for excellence in genetics and genomics research, it matters how the funding and ideas are brought to bear on tractable problems. Different nations have different priorities and strategies. Consequently, we are hoping that the Kuwait Foundation for the Advancement of Science and the newly formed Research Council of Oman, too, will be able to get value for their money through solid support for outstanding researchers and then to scale up selectively in timely response to particularly productive and locally apt research programs.

Were the scientists themselves to help shape policy, they would steer the legislators away from labyrinthine reporting and performance requirements, pointing out that time taken to complete many administrative tasks is stolen from their research, itself often undertaken in hours borrowed from the clinic. Requiring competitive bidding for equipment contracts may indeed reduce costs, but this may be a false economy if multiple rounds of bidding drag on well into a fixed funding period. Certainly, researchers would dissuade politicians from reinventing ethical review by creating local review board rules incompatible with international collaboration at a time when there is nearly universal agreement on bioethical principles and their implementation. They would point out that some projects offer rich collaborative environments or else are spitting out new questions and strategies like biological reactors, making them more suitable than the average research program to provide strong training for students.

Scientists advising legislators would point out that laws banning the export of samples from a country lacking the infrastructure to process them not only plays havoc with research collaborations but also impedes efforts at capacity building. Without such misguided legislation, sample collectors can protect themselves, and their research subjects anxious for results, by offering their collaborators a limited time period and explicit plan of their overall aims for analysis. Similarly, collaborators who find their approach has not yielded results with a particular set of samples should perhaps generate goodwill for future collaborations by rapidly letting them go to other partners who are able to try a different technology.

One proposal is for scientists to take the initiative by organizing evidence-based policy workshops, looking for solutions elsewhere and inviting regional and international policymakers who have a track record of enabling healthcare investment and research funding. A complementary home-grown approach is to treat evidence-based policy discussions like interdisciplinary research, producing versioned standards of practice, milestones and targets for one another and holding regular handshaking meetings between the research and legislative stakeholders.

Researchers in the Middle East are certainly grateful for the regional funding initiatives. And the grumbling sounds currently audible seem, in fact, much like the rumble of acceleration. 